\title{
Tectonic plates parameters estimated in International Terrestrial Reference Frame ITRF2008 based on DORIS stations
}

\author{
Katarzyna Kraszewska ${ }^{1} \cdot$ Marcin Jagoda $^{1} \cdot$ Miłosława Rutkowska $^{1}$
}

Received: 22 June 2017 / Accepted: 2 June 2018 / Published online: 19 June 2018

(C) The Author(s) 2018

\begin{abstract}
This paper concerns an analysis of the accuracy of the estimated parameters $\Omega(\Phi, \Lambda, \omega)$ which define the tectonic plate motions. The study is based on the velocities of station positions in the IERS (International Earth Rotation and Reference Systems Service) which has published new realization of the International Terrestrial Reference System-ITRF2008 for Doppler Orbitography by Radiopositioning Integrated on Satellite DORIS technique. Eurasian, African, Australian, North American, Australian, Pacific, Antarctic and South American plates were used in the analysis. The influence of the number and localization of stations on the plate surface on the estimation accuracy of the tectonic plate motion parameters were discussed. The results were compared with the APKIM 2005 IGN model and our earlier estimation for the SLR technique. In general, a remarkable concurrent agreement between the present and the APKIM 2005 solutions was found.
\end{abstract}

Keywords ITRF · DORIS · Plate tectonics parameters

\section{Introduction}

This paper is the second part of the cycle concerning an analysis of the parameters of tectonic plate estimation on the base of four geodetic satellite techniques, VLBI, SLR, GPS and DORIS. This part applies to DORIS technique.

ITRF2008 is a version of the International Terrestrial Reference Frame based on the combined solutions for four space geodetic techniques: VLBI, SLR, GPS and DORIS spanning 29, 26, 12.5 and 16 years of observations, respectively (Altamimi et al. 2011). The ITRF2008 network comprises 934 stations located at 580 sites, with 463 in the northern hemisphere and 117 in the southern hemisphere. All SLR, GPS, DORIS and VLBI techniques offer determination of three-dimensional station positions with accuracies of a few $\mathrm{mm}$ and the coordinate velocities of

Katarzyna Kraszewska

katarzyna.kraszewska@tu.koszalin.pl

Marcin Jagoda

marcin.jagoda@tu.koszalin.pl

Miłosława Rutkowska

miloslawa.rutkowska@tu.koszalin.pl

1 Technical University of Koszalin, Śniadeckich 2, 75-453 Koszalin, Poland
$1 \mathrm{~mm} /$ year from continuous observations in the time interval $\Delta \mathrm{t}$ or repeated observations after the time interval $\Delta \mathrm{t}$. Our idea is to estimate tectonic plate motion parameters using the three above-mentioned techniques separately and to compare the results of estimation (accuracy and stability) solutions. In the first paper, the SLR technique given in (Kraszewska et al. 2016) was investigated. In this paper, the network of DORIS stations shown in Fig. 1 was analyzed. Generally, this technique is based on measurement data for geophysical satellites SPOT1-5, TOPEX/Poseidon, Jason1-3, Envisat and others. The method of satellite orbits, station positions and velocities estimation for all techniques is given in (Altamimi et al. 2011), but on the basis of the SLR technique is described, e.g., in Lejba and Schillak (2011), Rutkowska and Jagoda (2010), Sośnica (2014). Methodology and data analysis for the DORIS technique are described in details by (Cretaux et al. 1998) and (Soudarin and Cretaux 2005).

Our idea is to estimate tectonic plate motion parameters for each technique separately and compare the obtained results. 


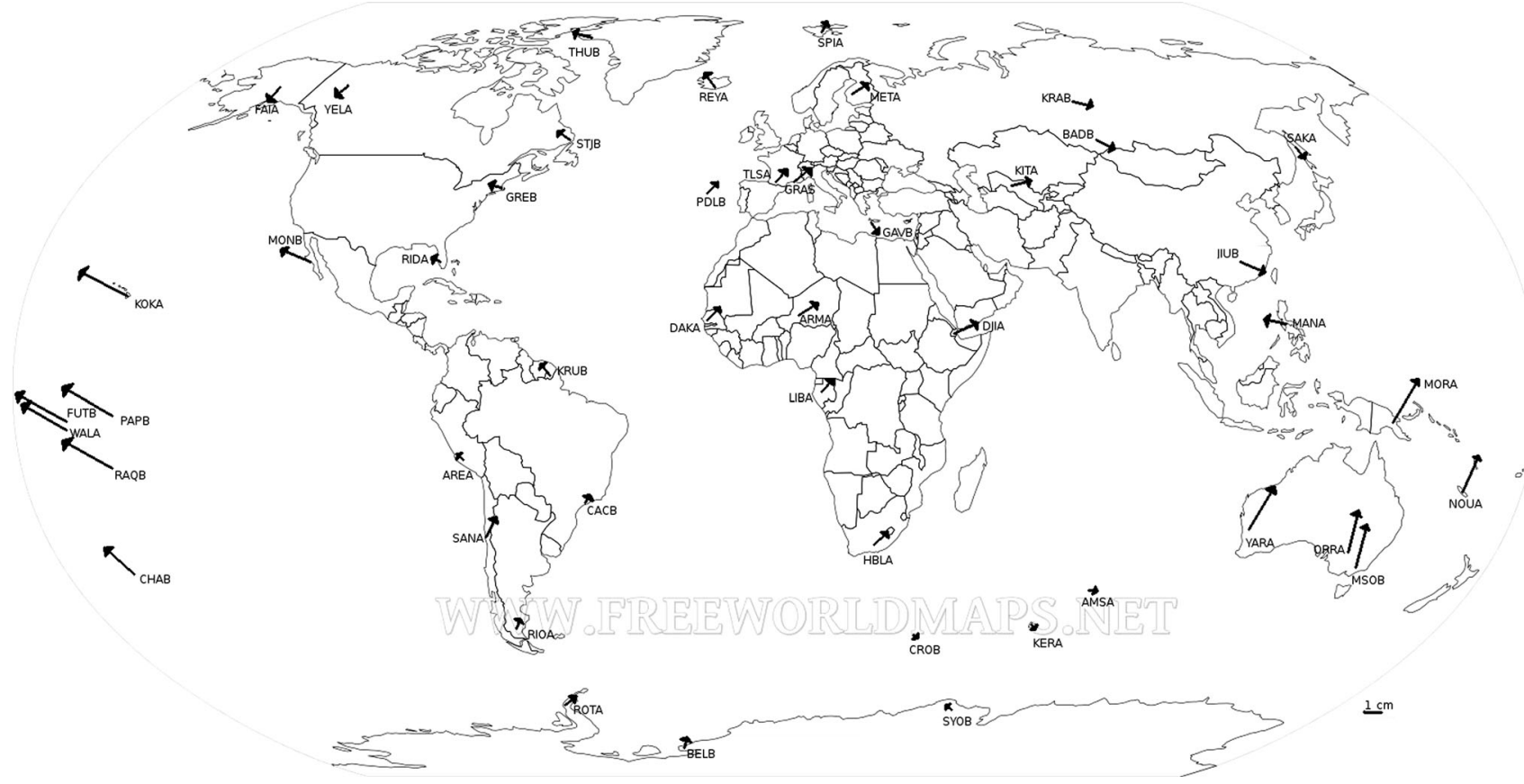

Fig. 1 Station positions and velocity vectors used for the estimation of tectonic plates parameters of the Eurasian, African, Australian, North American, Pacific, Antarctic and South American plates

\section{A short description of DORIS technique}

The French civil Doppler Orbitography by Radiopositioning Integrated on Satellite system DORIS was designed by the French Space Agency CNES in cooperation with French Mapping and Survey Agency IGN and the Space Geodesy Research Institute GRGS.

DORIS mission includes satellites SPOT 1-5, TOPEX/ Poseidon, Jason 1-3, Envisat and other carrying high precise onboard instruments (an antenna, a radio receiver and an oscillator ultra-stable). The DORIS antenna onboard of satellites receives signals emitted at the frequency of 401.25 MHz and $2036.25 \mathrm{MHz}$ by the terrestrial station network (beacons). Measurements enable to calculate the distance between the beacon on the ground and the transmitting satellite. The DORIS system perfectly corresponds to the specifications required for the ocean topography observations and the amplitude of the observed phenomena: it now enables to measure the satellite position with high precision on its orbit close to $1 \mathrm{~cm}$.

The DORIS system now includes about 60 stations (ground beacons) spread around the globe, in an international network of autonomous stations used as reference points on the ground. Half of them is installed on island or coastal areas or in the boundary of plates, allowing homogeneous coverage including the northern and southern hemisphere. DORIS ground stations are composed of a beacon (three generations). The ground station network is composed of several kinds of beacons: permanent beacons and mobile beacons. As an example, Toulouse, Kourou, Hartebeesthoek stations belong to the permanent network.

A unique DORIS network of ground stations and its highly accurate positioning capability have also proven to be greatly valuable for geodesy and geophysics applications: determining the orbit of satellites, measuring the continental drift, fitting the local geodetical network, monitoring geophysical deformations, determining the rotation and the gravity parameters of the earth and contributing to the international reference system.

The estimation and scientific analysis of the tectonic plate motions parameters are the subject of this paper.

The DORIS realization of ITRF2008 is based on weekly SINEX files from the epoch 1993.0 to 2009.0 (IERS Technical Note 37). The observations from satellites are sent to IDS (International DORIS Service) combinations center. SINEX files include stations positions and Earth Orientation Parameters (EOP). Based on them, IDS combination center estimated cumulative stations positions and velocities.

\section{The method of the estimation of tectonic plates parameters}

The plate motion parameters can be described by angular velocities $\left(\omega_{x}, \omega_{y}, \omega_{z}\right)$ or by the rotation vector $\Omega$ represented by the geographical position of the rotation pole $(\Phi$, $\Lambda)$ and the rotation velocity $(\omega)$ described by (Drewes 
1989) (Cox and Hart 1986) (Van Gelder and Aardoom 1982). The tectonic plate motion parameters are the function of the station displacements.

The observation equations used in method of the least squares adjustment allow to estimate the plate motion parameters from the shifts of selected station positions and velocities given in (Drewes 1982).

$v_{\varphi}=\left(\frac{\partial \Delta \varphi}{\partial \Phi}\right) \mathrm{d} \Phi+\left(\frac{\partial \Delta \varphi}{\partial \Lambda}\right) \mathrm{d} \Lambda+\left(\frac{\partial \Delta \varphi}{\partial \omega}\right) \mathrm{d} \omega-\left(\Delta \varphi^{\mathrm{obs}}-\Delta \varphi^{\mathrm{cal}}\right)$

$v_{\lambda}=\left(\frac{\partial \Delta \lambda}{\partial \Phi}\right) \mathrm{d} \Phi+\left(\frac{\partial \Delta \lambda}{\partial \Lambda}\right) \mathrm{d} \Lambda+\left(\frac{\partial \Delta \lambda}{\partial \omega}\right) \mathrm{d} \omega-\left(\Delta \lambda^{\text {obs }}-\Delta \lambda^{\text {cal }}\right)$

A system of equations can be solved if a sufficient number of observations is available. For the estimation parameters of the plate motion at minimum two stations on each plate are necessary. If the number of stations is greater, the unknowns can be solved using the least square method according to the known expression.

$\Omega=\left[\begin{array}{l}\Phi \\ \Lambda \\ \omega\end{array}\right]=\left(A^{T} P A\right)^{-1} A^{T} P L$

where $A$ matrix of partial derivatives given by expressions, $P$ matrix of measurement weights, $L$ matrix of $\left(\Delta \varphi^{\text {obs- }}\right.$ $\left.-\Delta \varphi^{\mathrm{cal}}\right)$ or $\left(\Delta \lambda^{\mathrm{obs}}-\Delta \lambda^{\mathrm{cal}}\right)$.

The sequential method was adopted for the analysis. In the first step, the tectonic plate parameters were adjusted for two or three stations which were located on each plate. In subsequent steps, stations, one after the other, were included and added to the solution. In each step, the parameters were adjusted once again, enabling the stability parameters and their errors to be observed. It is shown in Figs. 2a-c (for the Eurasian plate), 3a, b, c (for the African plate) $4 \mathrm{a}-\mathrm{c}$ (for the Australian plate), $5 \mathrm{a}-\mathrm{c}$ (for the North American plate), 6a-c (for the Pacific plate), $7 \mathrm{a}-\mathrm{c}$ (for the Antarctic plate) and $8 \mathrm{a}-\mathrm{c}$ (for the South American plate). The final estimated unknowns $\Phi, \Lambda, \omega$ and their errors are shown in Table 8 and analyzed. The results of the analysis for each step are shown in Tables 1, 2, 3, 4, 5, 6, 7 for the Eurasian, African, Australian, North American, Pacific, Antarctic and South American plates, respectively.

The method of analysis for the SLR technique is described in details in (Kraszewska et al. 2016). The same method is used to the analysis of DORIS data. The computations were performed using our own program in FORTRAN90.

\section{Results}

\section{General description}

The paper presents the tectonic plate motion parameters $\Omega$ $(\Phi, \Lambda, \omega)$ for the Eurasian, African, Australian, North American, Pacific, Antarctic and South American plates which were adjusted using our computer software. Our idea of this paper is to show an influence of the station localization and quantity in each analyzed plate on the estimation accuracy of the plate motion parameters for DORIS technique and comparison with the other techniques. Our computations were performed on the basis of an improved solution of the International Terrestrial Reference Frame ITRF2008, adjusted and described in detail by (Altamimi et al. 2011). The geodetic coordinates $(\varphi, \lambda, h)$ for DORIS beacons are transformed from $(x, y$, $z$ ) according to the expressions described in (Heiskanen and Moritz 1981). The station coordinates, velocities caused by the tectonic plate motions for SLR, GPS, DORIS and VLBI techniques were taken from the ITRF2008. Generally, it should be mentioned that the number of DORIS working stations is not large (about 50-60 on the Earth's surface), similar as for SLR technique. SLR stations are located in stable regions of the plates but not uniformly distributed-there is a large difference of the station numbers between the northern and the southern hemisphere. DORIS stations are uniformly distributed allowing homogeneous coverage including the northern and southern hemisphere but regrettably situated particularly in island or coastal areas and the boundary of the plates. In (Cretaux et al. 1998) the authors divided DORIS stations into three groups: those located in the stable plate interiors, those near the plate boundaries and those not used in the solution due to different errors. In our paper, this problem is investigated as well, particularly because the whole number of DORIS stations is not big equaling approximately 50 . The minimum number of stations which is needed for the estimation of the plate motion parameters is 2 . A greater number of stations allow adjusting the solution using the least squares method and decreases plate motion parameters accuracy. The stability of the solution is observed when a change of the estimated value in the next step is smaller than the value of the computed accuracy solution. The sequential method was adopted for the analysis. Beginning from the two stations solution, step-by-step next stations were added. This method allows investigating the stability of the estimated parameters and the influence of each station on accuracy of plate motion parameters separately. The selection of the stations was based on the following criterion: first stations located in the 
Fig. 2 a Estimated parameter $\Phi$ and its error of the Eurasian plate motion for DORIS network based on 11 selected stations using the least square sequential solution. b Estimated parameter $\Lambda$ and its error of the Eurasian plate motion for DORIS network based on 11 selected stations using the least square sequential solution. c Estimated parameter $\omega$ and its error of the Eurasian plate motion for DORIS network based on 11 selected stations using the least square sequential solution (a)

$\Phi$

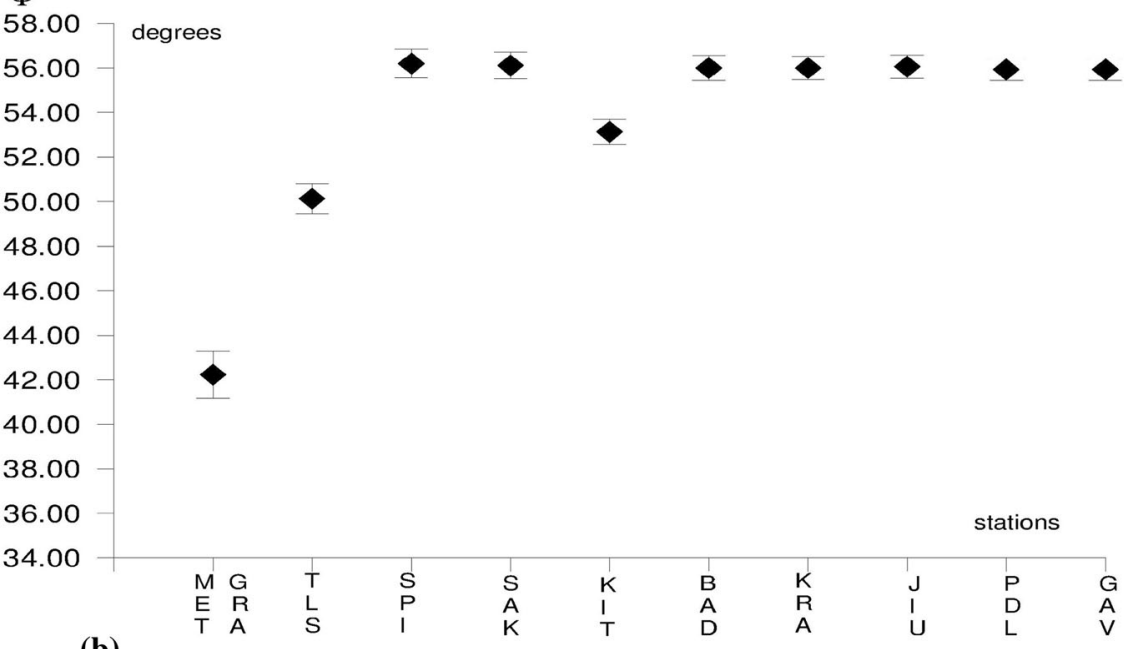

(b)

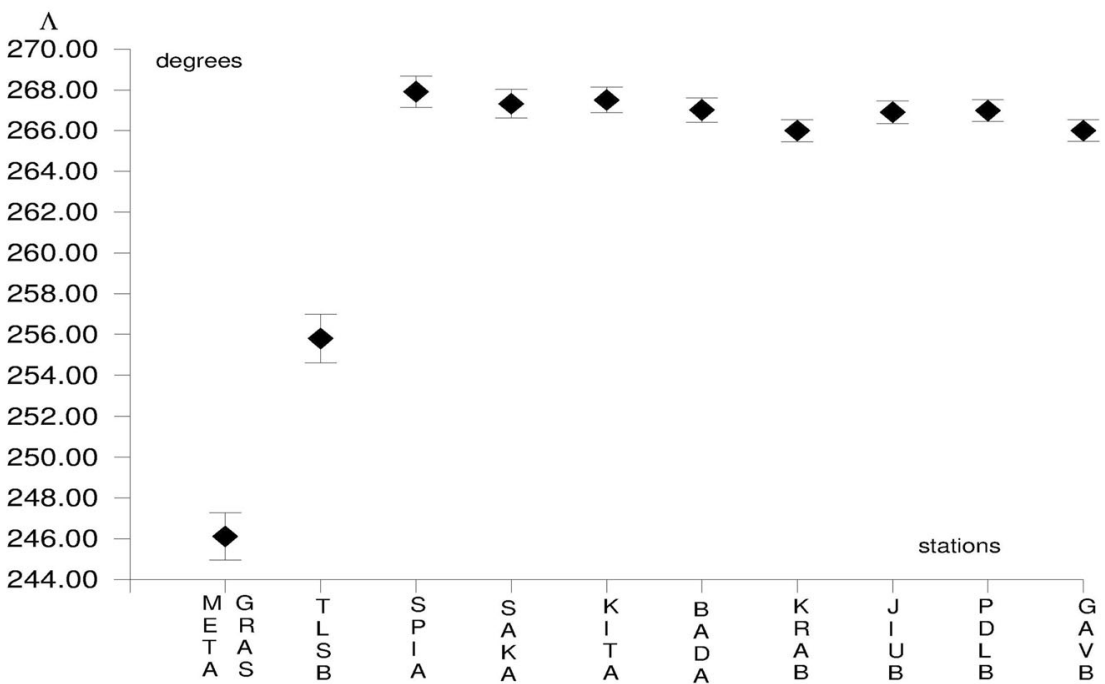

(c)

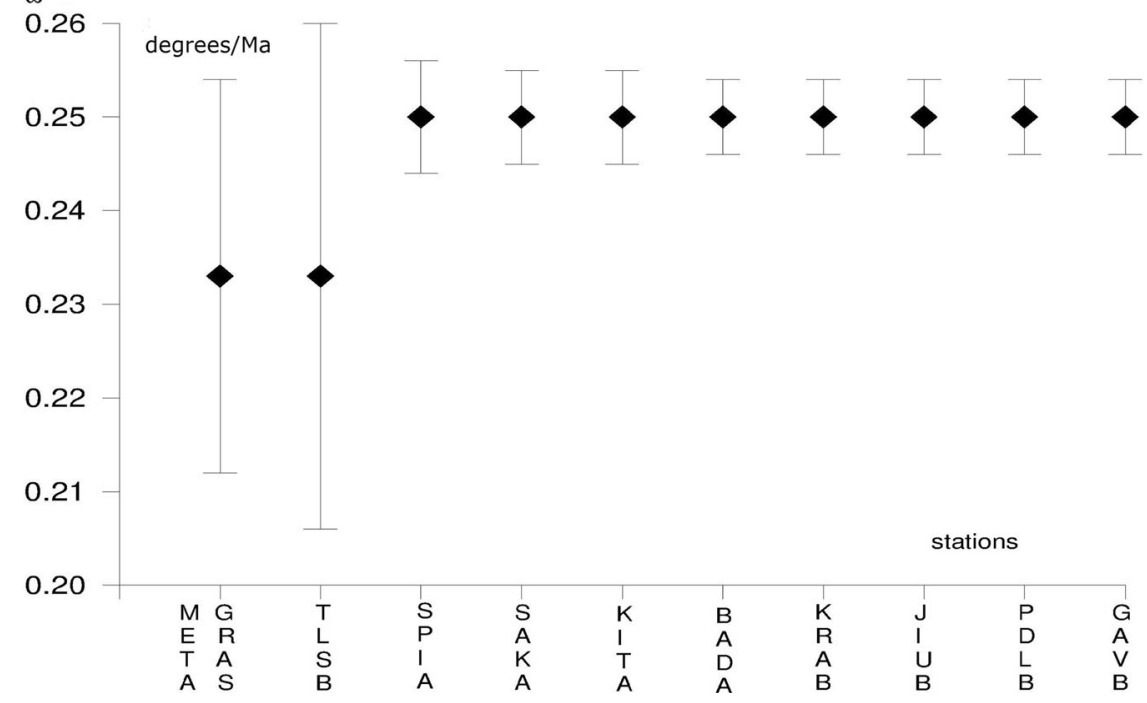



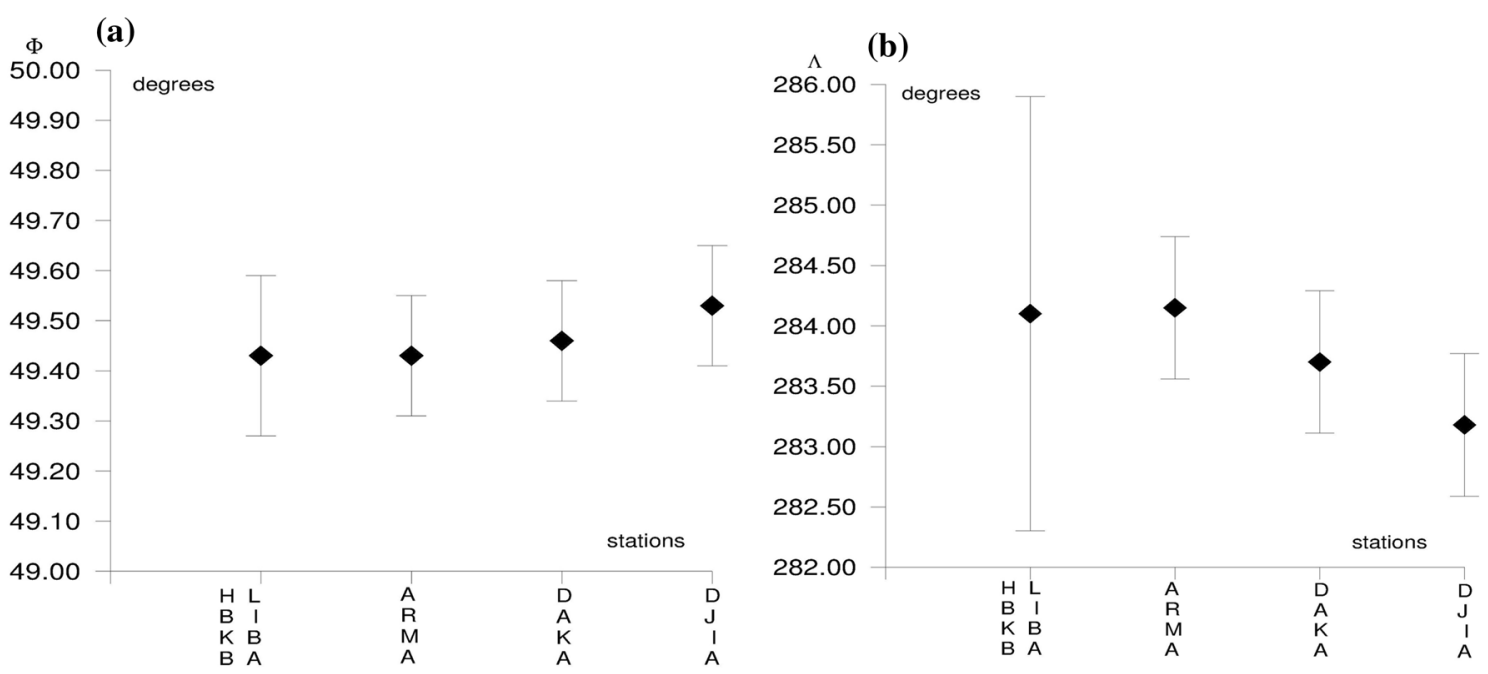

(c)

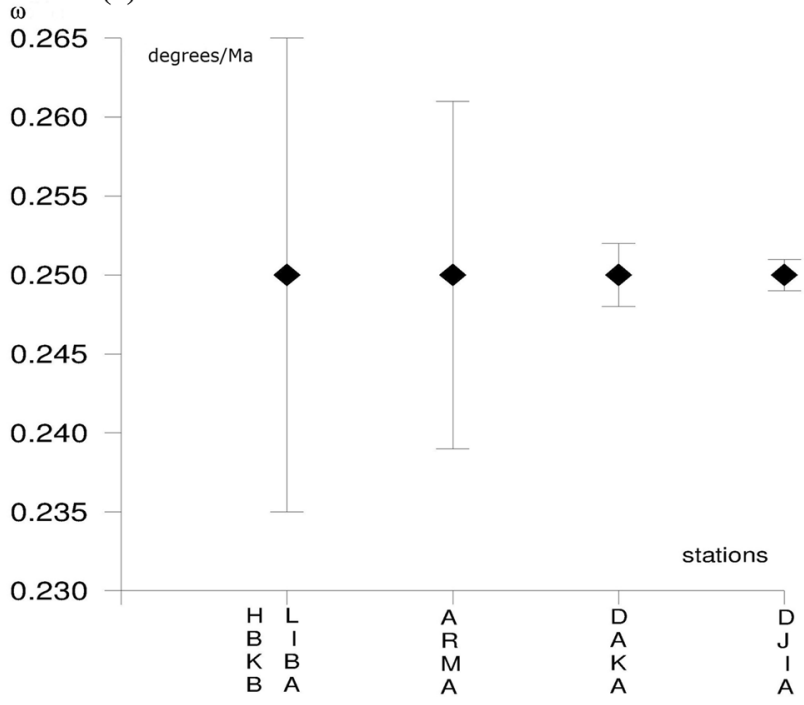

Fig. $3 \mathbf{a}$ and $\mathbf{b}$ Estimated parameters $\Phi$ and $\Lambda$ and its errors of the African plate motion for DORIS network based on five selected stations using the least square sequential solution. c Estimated

stable region of the plate were included; next stations located near the plate boundary were included but not disturbing the solution accuracy.

\section{Detailed analysis of plate motion parameters}

Generally, in the analysis the position and velocity of DORIS stations adjusted with high accuracy taken from ITRF2008 were used. In the European plate, only twelve DORIS stations are situated (Metsahovi, Grasse, Touluose, Ny-Alesund, Youzhno- Sakhalin, Kitab, Badary, Krasnoyarsk, Wuhan-Jiufeng, Ponta Delgada, Gavdos, Everest). Six stations are located on the European continent, and six stations are located on the Asiatic continent. The Everest parameter $\omega$ and its error of the African plate motion for DORIS network based on five selected stations using the least square sequential solution

station is located in a very seismic and unstable region, and the shift of this station is not concordant with the Eurasian plate motion. The inclusion of this station in the adjustment is due to a big systematic error. It explains switching off this station from adjustment. Shifts for Eurasian stations are given in Fig. 1. On the basis of eleven stations, the final estimated plate motion parameters values equal to $\Phi=55.93^{\circ} \pm 0.50^{\circ}, \quad \Lambda=266^{\circ} \pm 0.53^{\circ}, \quad \omega=0.250^{\circ} /$ $\mathrm{Ma} \pm 0.004^{\circ} / \mathrm{Ma}$ are given in Table 1 . Stability of the solution can be observed for about five stations. For the African plate, only five DORIS stations were investigated; it means all stations located on this plate. The first estimation was performed for two stations (Hartebeesthoek and Libreville). Next, the stations were included one after 
(a)

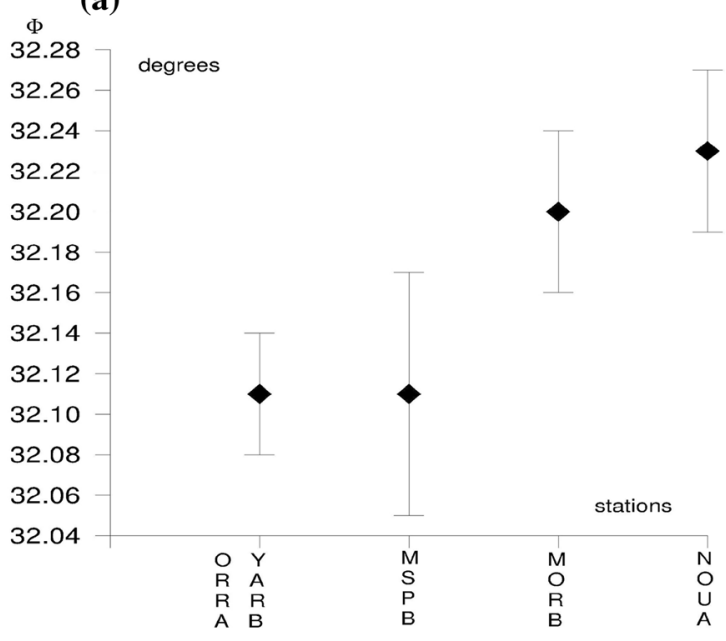

(c)

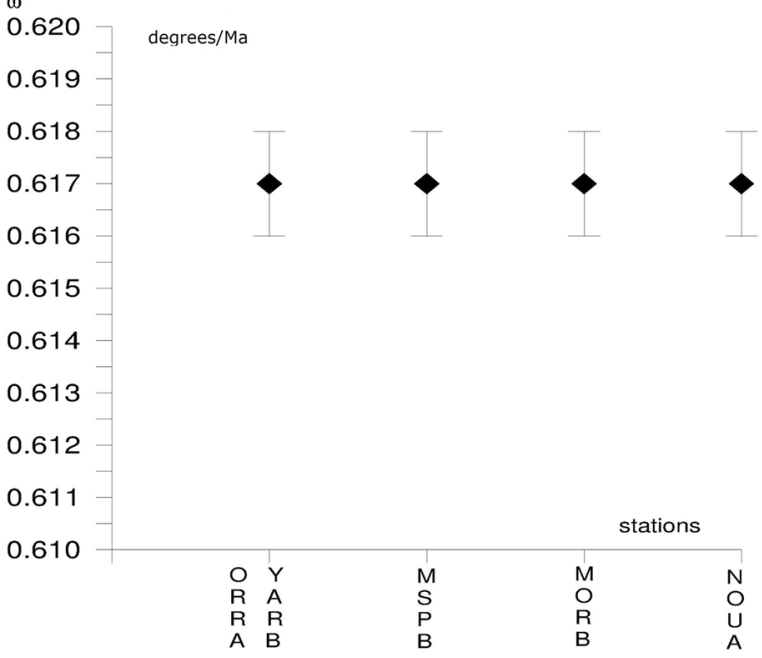

(b)

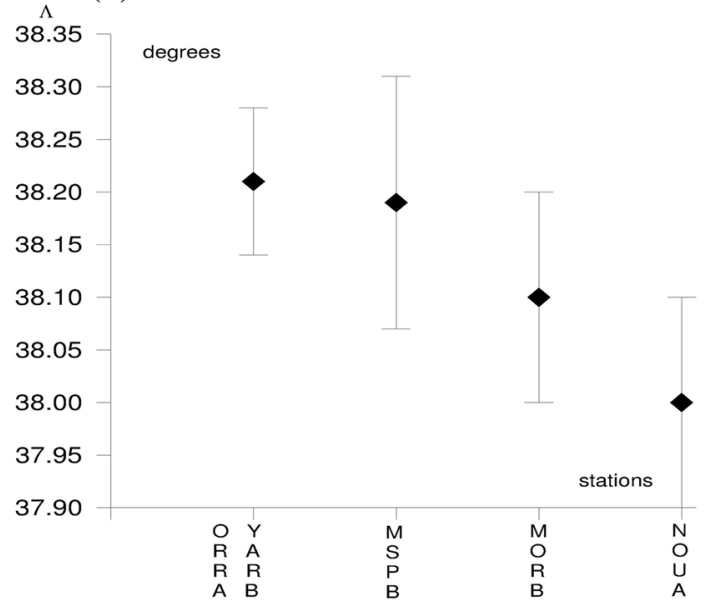

parameter $\omega$ and its error of the Australian plate motion for DORIS network based on five selected stations using the least square sequential solution

Fig. 4a-c and in Table 3. For the North American plate seven stations were used, four on continent: St John's, Yellowknife, Greenbelt, Fairbanks, Richmond and two on an island: Reykjavik, Thule shown in Fig. 1. The first estimation was performed for two stations Reykjavik and Thule; next St John's, Yellowknife, Greenbelt, Fairbanks and Richmond stations were added. Stability solution is observed for five stations shown in Fig. 5a-c. The final estimated values equal to $\Phi=-0.80^{\circ} \pm 0.82^{\circ}$, $\Lambda=279.50^{\circ} \pm 0.37^{\circ}, \omega=0.200^{\circ} / \mathrm{Ma} \pm 0.002^{\circ} / \mathrm{Ma}$ are given in Table 4. Differences between our solution for DORIS and SLR data (Kraszewska et al., 2016) are about 3-4 degrees. A similar difference can be observed for the APKIM 2005 IGN solution. For the Pacific plate eight stations were used (Kauai, Papeete, Futuna, Rapa, Chatham Island, Manila, Wallis). Stability of the solution is observed 
(a)

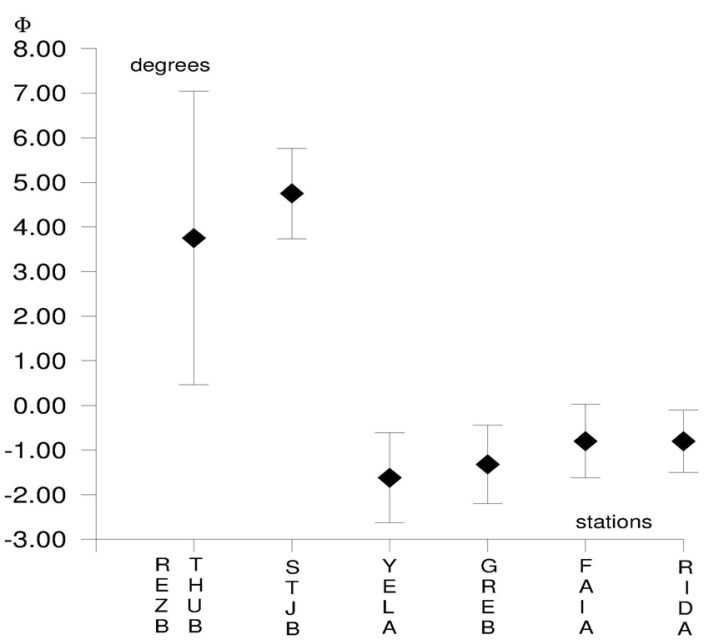

(b)

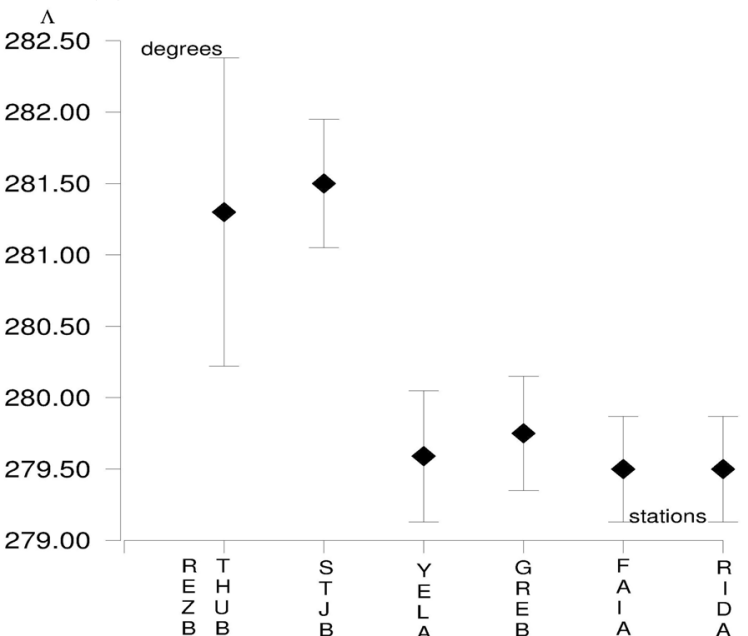

(c)

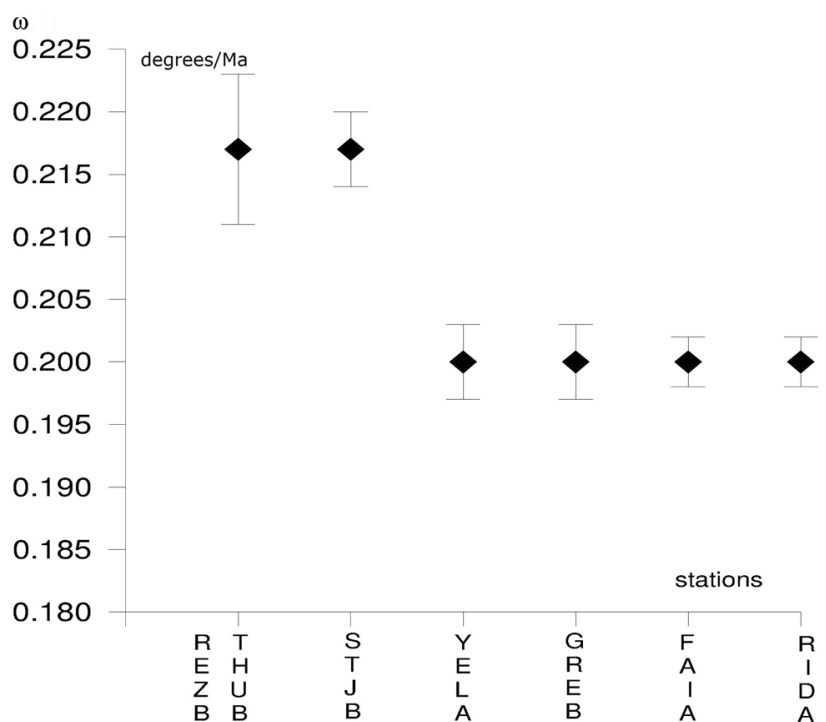

Fig. 5 a and b Estimated parameter $\Phi$ and $\Lambda$ and its error of the North American plate motion for DORIS network based on six selected stations using the least square sequential solution. c Estimated

for six stations. Final estimated values are equal to $\Phi=-62.20^{\circ} \pm 0.85^{\circ}, \Lambda=113.70^{\circ} \pm 3.81^{\circ}, \omega=0.650^{\circ} \%$ $\mathrm{Ma} \pm 0.002^{\circ} / \mathrm{Ma}$. For the Antarctic plate six stations were used, four on continent: Syowa, Rothea, Belgrano, Kergulen, and two on an island: Amsterdam, Ile de la Posse (CROZET) shown in Fig. 1. The first estimation was performed for two stations, Syowa and Rothea; next Belgrano, Kergulen, Amsterdam and Ile de la Posse (CROZET) stations were added. Stability of the solution is observed for five stations shown in Fig. 7a-c. The final estimated values equal to $\Phi=60.28^{\circ} \pm 0.23^{\circ}, \quad \Lambda=235.10^{\circ} \pm 0.61^{\circ}$, $\omega=0.250^{\circ} / \mathrm{Ma} \pm 0.006^{\circ} / \mathrm{Ma}$ are given in Table 6 .

For the South American plate only five DORIS stations are located. Arequipa is located in an unstable and very parameter $\omega$ and its error of the North American plate motion for DORIS network based on six selected stations using the least square sequential solution

seismic region. The shift of this station does not agree with the South American plate motion and due to a great error of adjustment has to be rejected from the solution. The solution is analyzed for four remaining stations: Cachoeira Pauli, Rio Grande, Kourou and Santiago, but it is not sufficient for good quality adjustment. For the last station agreement with the previous solution can be observed; it can be seen in Fig. 8a-c. The final estimated values equal to $\quad \Phi=-20.25^{\circ} \pm 1.74^{\circ}, \quad \Lambda=238.31^{\circ} \pm 1.57^{\circ}$, $\omega=0.133^{\circ} / \mathrm{Ma} \pm 0.007^{\circ} / \mathrm{Ma}$ are given in Table 7 . Agreement with APKIM2005 IGN is good, but it is very difficult to conclude on the basis of four stations only.

The final estimated values of the plate motion parameters for Eurasian, African, Australian, North American, 


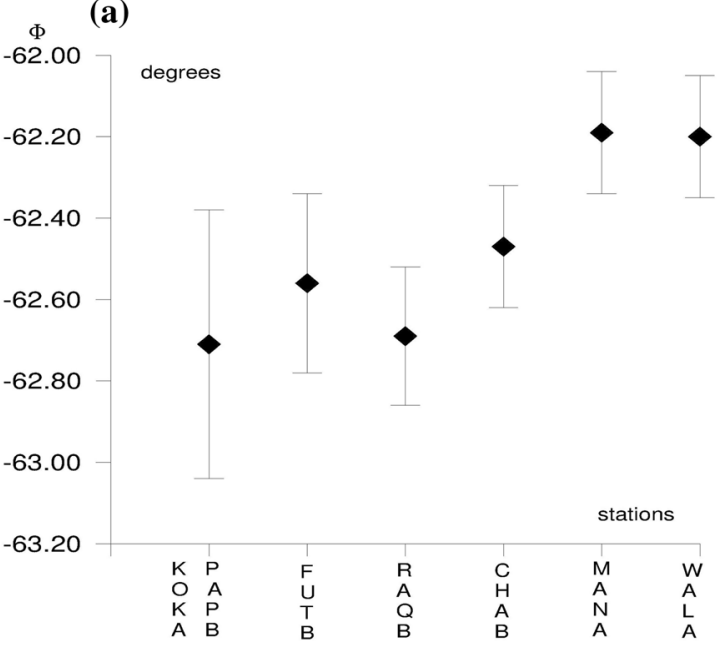

(b)
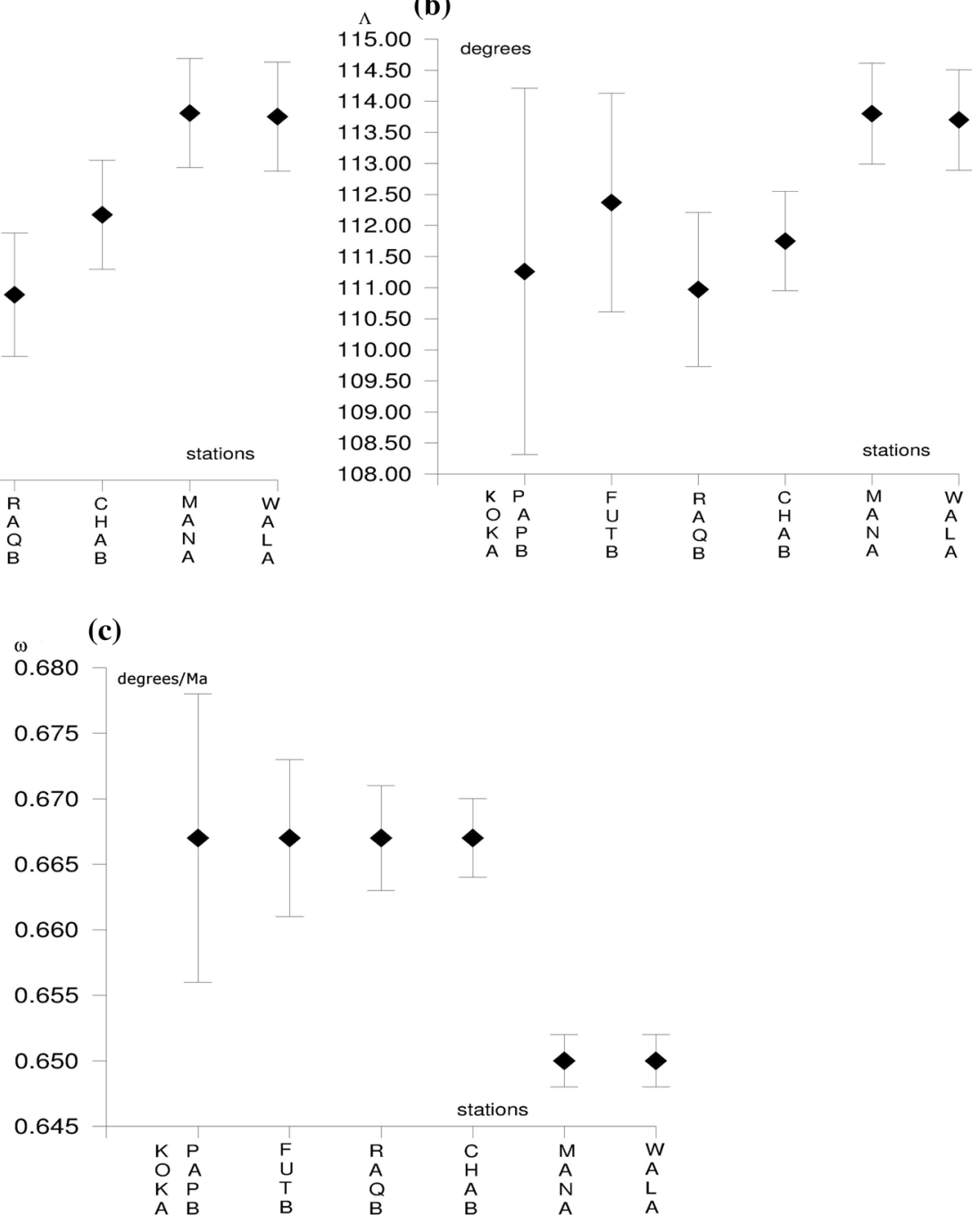

Fig. $6 \mathbf{a}$ and b Estimated parameter $\Phi$ and $\Lambda$ and its error of the Pacific plate motion for DORIS network based on seven selected stations using the least square sequential solution. c Estimated

parameter $\omega$ and its error of the Pacific plate motion for DORIS network based on seven selected stations using the least square sequential solution

Pacific, Antarctic and South American plates are given in Table 8, and they are compared with Drewes (2009) solution (model APKIM 2005 IGN). These both solutions are compared with our previous solution for the SLR technique given in (Kraszewska et al. 2016) and can be compared with solution performed by Larson et al. (1997) on the base GPS technique only. Agreement in spite of different techniques and localization of stations used to analysis is in the order a few degrees.

The computation was performed using our own FORTRAN 90 software. This program is based on theory of the least squares adjustment of plate motion parameters from coordinate shifts of selected station positions and velocities. A system of two equations given in chapter 3 can be solved if sufficient number of observations is available. For estimating the plate motion parameters, minimum two points on each plate are needed. The greater number of

stations on each plate allows to analyze influence of number and localization of stations on estimation of plate motion parameter value and accuracy. Sequential method used in solution is described in chapter 3 .

\section{Conclusions}

On the basis of the performed analysis, the following conclusions can be drawn:

- Regular distribution of station positions is recommended for each tectonic plate; concentration of a high number of stations in a small area does not cause an increase in the solution accuracy.

- The number of DORIS stations located on the Earth globe is similar to the number of SLR stations; it is 
(a)

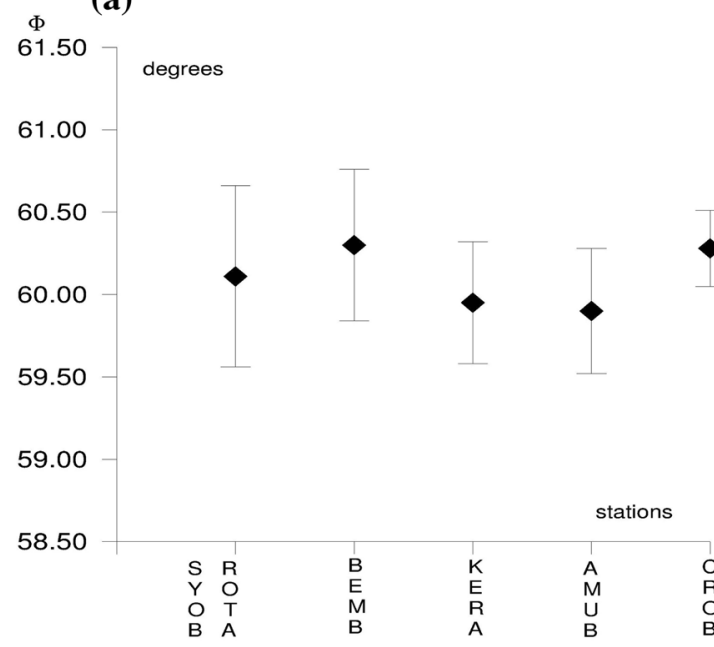

(c)

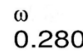

0.280
0.275

0.270

0.265

0.260

0.255

0.250

0.245

0.240

0.235

0.230

0.225

0.220

0.215

0.210

0.205

0.200

degrees/Ma

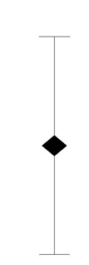

(b)

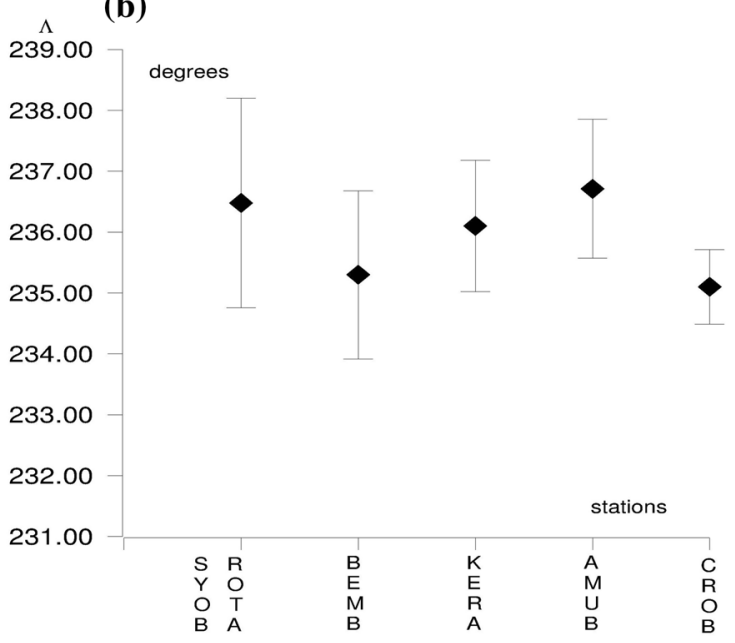

$\sqrt{1}$

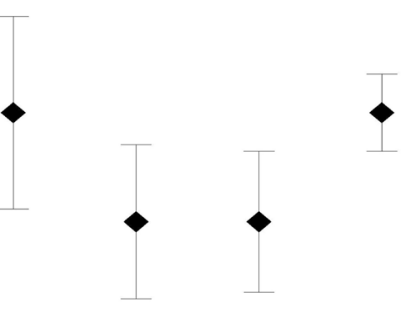

Fig. 7 a and b Estimated parameter $\Phi$ and $\Lambda$ and its error of the Antarctic plate motion for DORIS network based on six selected stations using the least square sequential solution. c Estimated

parameter $\omega$ and its error of the Antarctic plate motion for DORIS network based on six selected stations using the least square sequential solution

shown in (Kraszewska et al. 2016), but localization of stations is significantly different. The majority of DORIS stations are located near the plate boundary or in a region with seismic activity. Due to shifts of these stations, it does not agree with the whole plate motion. These stations have to be removed from the solution. The following stations were removed: for the Eurasian plate-Everest (EVEB), Gavdos (GAVB), for the North American plate-Monument Peak (MONB), for the South American-Arequipa (ARFB). It is due to the diminishment in the number of stations used in the solution. The sequential method used in the analysis allows to detect stations with their own motion inconsistent with the motion of the whole plate.

- A remarkable concurrence of the estimated parameters $(\Phi, \Lambda, \omega)$ for DORIS technique and APKIM 2005 IGN

model can be seen in (Table 8) in spite of a small number of DORIS stations located on the Earth's surface. Maximum differences are of the order of 2 degrees for the Eurasian, African and Australian plates. For the other plates differences are greater.

- Stabilization of the estimated tectonic plate parameters and their random distribution of errors for about 7-8 stations situated on each plate can be noticed. As an example the Eurasian, North American and Pacific plates with the number of stations 11, 6, 7, respectively, are shown. The African, Australian, Antarctic and South American plates are analyzed for 4-6 stations located on the plate only. For the African and Antarctic plates, the differences between the last and the previous iteration are smaller than the values of errors. For the South American plate, an analysis is performed for four 

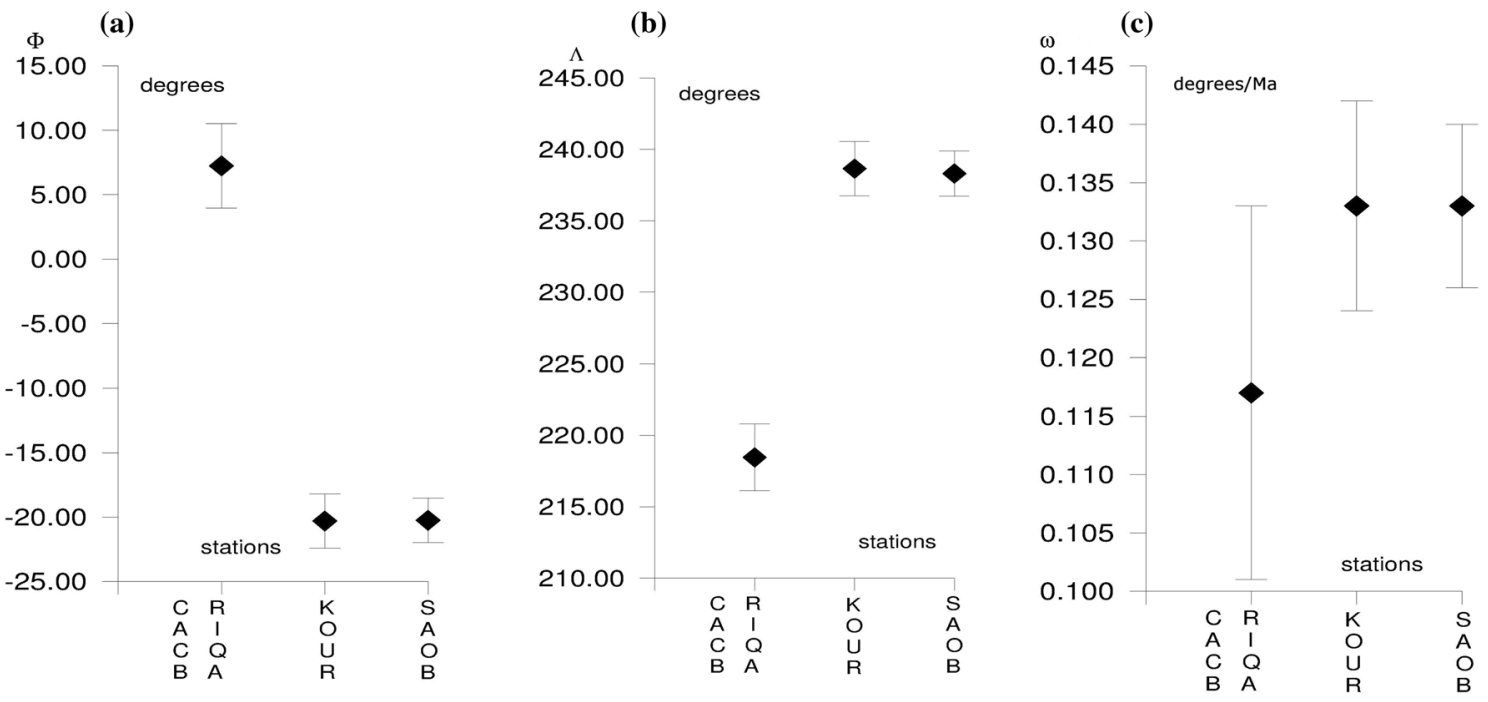

Fig. 8 a, b and $\mathbf{c}$ Estimated parameter $\Phi, \Lambda$ and $\omega$ and its error of the South American plate motion for DORIS network based on three selected stations using the least square sequential solution

Table 1 Estimated plate parameters and its error of the Eurasian plate motion for DORIS network based on eleven selected stations using the least squares sequential solution

Eurasian plate

Parameters of the tectonic plate displacement $\Omega(\Phi, \Lambda, \omega)$

\begin{tabular}{lllll}
\hline No & Name and number of the station & $\Phi\left({ }^{\circ}\right)$ & $\Lambda\left(^{\circ}\right)$ & $\omega\left({ }^{\circ} / \mathrm{Ma}\right)$ \\
\hline 2 & Metsahovi META (1) + Grasse GRAS (2) & $42.23 \pm 1.06$ & $246.11 \pm 1.16$ & $0.233 \pm 0.021$ \\
3 & $(1)+(2)+$ Touluose TLSB (3) & $50.13 \pm 0.67$ & $255.80 \pm 0.19$ & $0.233 \pm 0.027$ \\
4 & $(1)+(2)+(3)+$ Ny-Alesund SPIA (4) & $56.20 \pm 0.65$ & $267.91 \pm 0.77$ & $0.250 \pm 0.006$ \\
5 & $(1)+(2)+(3)+(4)+$ Yuzhno-Sakhalin SAKA (5) & $56.11 \pm 0.60$ & $267.32 \pm 0.70$ & $0.250 \pm 0.005$ \\
6 & $(1)+(2)+(3)+(4)+(5)+$ Kitab KITA (6) & $53.13 \pm 0.56$ & $267.50 \pm 0.63$ & $0.250 \pm 0.005$ \\
7 & $(1)+(2)+(3)+(4)+(5)+(6)+$ Badary BADA (7) & $56.00 \pm 0.56$ & $267.01 \pm 0.60$ & $0.250 \pm 0.004$ \\
8 & $(1)+(2)+(3)+(4)+(5)+(6)+(7)+$ Krasnoyarsk KRAB (8) & $56.00 \pm 0.52$ & $266.00 \pm 0.55$ & $0.250 \pm 0.004$ \\
9 & $(1)+(2)+(3)+(4)+(5)+(6)+(7)+(8)+$ Wuhan-Jiufeng JIUB (9) & $56.06 \pm 0.52$ & $266.90 \pm 0.55$ & $0.250 \pm 0.004$ \\
10 & $(1)+(2)+(3)+(4)+(5)+(6)+(7)+(8)+(9)+$ Ponta Delgada PDLB (10) & $55.93 \pm 0.50$ & $266.98 \pm 0.53$ & $0.250 \pm 0.004$ \\
11 & $(1)+(2)+(3)+(4)+(5)+(6)+(7)+(8)+(9)+(10)+$ Gavdos GAVB (11) & $55.93 \pm 0.50$ & $266.00 \pm 0.53$ & $0.250 \pm 0.004$ \\
\hline
\end{tabular}

Table 2 Estimated plate parameters and its error of the African plate motion for DORIS network based on five selected stations using the least squares sequential solution

African plate

Parameters of the tectonic plate displacement $\Omega(\Phi, \Lambda, \omega)$

\begin{tabular}{lllll}
\hline No & Name and number of the station & $\Phi\left(^{\circ}\right)$ & $\Lambda\left(^{\circ}\right)$ & $\omega\left(^{\circ} / \mathrm{Ma}\right)$ \\
\hline 2 & Hartebeesthoek HBLA (1) + Libreville LIBA (2) & $49.43 \pm 0.16$ & $284.10 \pm 1.80$ & $0.250 \pm 0.015$ \\
3 & $(1)+(2)+$ Arlit ARMA (3) & $49.43 \pm 0.12$ & $284.15 \pm 0.59$ & $0.250 \pm 0.011$ \\
4 & $(1)+(2)+(3)+$ Dakar DAKA (4) & $49.46 \pm 0.12$ & $283.70 \pm 0.59$ & $0.250 \pm 0.002$ \\
5 & $(1)+(2)+(3)+(4)+$ Djibuti DJIA (5) & $49.53 \pm 0.12$ & $283.18 \pm 0.59$ & $0.250 \pm 0.001$ \\
\hline
\end{tabular}


Table 3 Estimated plate parameters and its error of the Australian plate motion for DORIS network based on six selected stations using the least squares sequential solution

Australian plate
\begin{tabular}{lllll}
\hline Parameters of the tectonic plate displacement $\Omega(\Phi, \Lambda, \omega)$ & & \\
\hline No & Name and number of the station & $\Phi\left({ }^{\circ}\right)$ & & \\
\hline 2 & Tidbinbilla ORRA (1) + Yarragadee YARB (2) & $32.11 \pm 0.03$ & $38.21 \pm 0.07$ & $0.617 \pm 0.001$ \\
3 & $(1)+(2)+$ Mount Stromlo MSPB (3) & $32.11 \pm 0.06$ & $38.19 \pm 0.12$ & $0.617 \pm 0.001$ \\
4 & $(1)+(2)+(3)+$ Fort Moresby MORB (4) & $32.20 \pm 0.06$ & $38.10 \pm 0.14$ & $0.617 \pm 0.001$ \\
5 & $(1)+(2)+(3)+(4)+$ Noumea NOUA (5) & $32.23 \pm 0.07$ & $38.00 \pm 0.14$ & $0.617 \pm 0.001$ \\
\hline
\end{tabular}

Table 4 Estimated plate parameters and its error of the North American plate motion for DORIS network based on six selected stations using the least squares sequential solution

North American plate

Parameters of the tectonic plate displacement $\Omega(\Phi, \Lambda, \omega)$

\begin{tabular}{llrrr}
\hline No & Name and number of the station & $\Phi\left(^{\circ}\right)$ & $\Lambda\left(^{\circ}\right)$ & $\omega\left({ }^{\circ} / \mathrm{Ma}\right)$ \\
\hline 2 & Reykjavik REZB (1) + Thule THUB (2) & $3.75 \pm 3.29$ & $281.30 \pm 1.08$ & $0.217 \pm 0.006$ \\
3 & $(1)+(2)+$ ST John's STJB (3) & $4.75 \pm 1.01$ & $281.50 \pm 0.45$ & $0.217 \pm 0.003$ \\
4 & $(1)+(2)+(3)+$ Yellowknife YELA (4) & $-1.62 \pm 1.01$ & $279.59 \pm 0.46$ & $0.200 \pm 0.003$ \\
5 & $(1)+(2)+(3)+(4)+$ Greenbelt GREB (5) & $-1.32 \pm 0.88$ & $279.75 \pm 0.40$ & $0.200 \pm 0.003$ \\
6 & $(1)+(2)+(3)+(4)+(5)+$ Fairbanks FAIA (6) & $-0.80 \pm 0.82$ & $279.50 \pm 0.37$ & $0.200 \pm 0.002$ \\
7 & $(1)+(2)+(3)+(4)+(5)+(6)+$ Richmond RIDA (7) & $-0.80 \pm 0.70$ & $279.50 \pm 0.37$ & $0.200 \pm 0.002$ \\
\hline
\end{tabular}

Table 5 Estimated plate parameters and its error of the Pacific plate motion for DORIS network based on eight selected stations using the least squares sequential solution

Pacific plate

Parameters of the tectonic plate displacement $\Omega(\Phi, \Lambda, \omega)$

\begin{tabular}{lllrr}
\hline No & Name and number of the station & $\Phi\left({ }^{\circ}\right)$ & $\Lambda\left(^{\circ}\right)$ & $\omega\left(^{\circ} / \mathrm{Ma}\right)$ \\
\hline 2 & Kauai KOKA (1) + Papeete PAPB (2) & $-62.71 \pm 0.33$ & $111.26 \pm 2.95$ & $0.667 \pm 0.011$ \\
3 & $(1)+(2)+$ Futuna FUTB (3) & $-62.56 \pm 0.22$ & $112.37 \pm 1.76$ & $0.667 \pm 0.006$ \\
4 & $(1)+(2)+(3)+$ Rapa RAQB (4) & $-62.69 \pm 0.17$ & $110.97 \pm 1.24$ & $0.667 \pm 0.004$ \\
5 & $(1)+(2)+(3)+(4)+$ Chatham Island CHAB (5) & $-62.47 \pm 0.15$ & $111.75 \pm 0.80$ & $0.667 \pm 0.003$ \\
6 & $(1)+(2)+(3)+(4)+(5)+$ Manila MANA (6) & $-62.19 \pm 0.15$ & $113.80 \pm 0.80$ & $0.650 \pm 0.002$ \\
7 & $(1)+(2)+(3)+(4)+(5)+(6)+$ Wallis WALA (7) & $-62.20 \pm 0.15$ & $113.70 \pm 0.81$ & $0.650 \pm 0.002$
\end{tabular}

Table 6 Estimated plate parameters and its error of the Antarctic plate motion for DORIS network based on six selected stations using the least squares sequential solution

Antarctic plate

Parameters of the tectonic plate displacement $\Omega(\Phi, \Lambda, \omega)$

\begin{tabular}{lllll}
\hline No & Name and number of the station & $\Phi\left({ }^{\circ}\right)$ & $\Lambda\left({ }^{\circ}\right)$ & $\omega\left({ }^{\circ} / \mathrm{Ma}\right)$ \\
\hline 2 & Syowa SYOB(1)+ Rothera ROTA (2) & $60.11 \pm 0.55$ & $236.48 \pm 1.72$ & $0.250 \pm 0.017$ \\
3 & $(1)+(2)+$ Belgrano BEMB(3) & $60.30 \pm 0.46$ & $235.30 \pm 1.38$ & $0.250 \pm 0.015$ \\
4 & $(1)+(2)+(3)+$ Kergulen KERA(4) & $59.95 \pm 0.37$ & $236.10 \pm 1.08$ & $0.233 \pm 0.012$ \\
5 & $(1)+(2)+(3)+(4)+$ Amsterdam AMUB (5) & $59.90 \pm 0.38$ & $236.71 \pm 1.14$ & $0.233 \pm 0.011$ \\
6 & $(1)+(2)+(3)+(4)+(5)+$ Ile de la Posse CBOB $(6)$ & $60.28 \pm 0.23$ & $235.10 \pm 0.61$ & $0.250 \pm 0.006$
\end{tabular}


Table 7 Estimated plate parameters and its error of the South American plate motion for DORIS network based on four selected stations using the least squares sequential solution

\begin{tabular}{|c|c|c|c|c|}
\hline \multicolumn{5}{|c|}{ South American plate } \\
\hline \multicolumn{5}{|c|}{ Parameters of the tectonic plate displacement $\Omega(\Phi, \Lambda, \omega)$} \\
\hline No & Name and number of the station & $\Phi\left({ }^{\circ}\right)$ & $\Lambda\left({ }^{\circ}\right)$ & $\omega\left({ }^{\circ} / \mathrm{Ma}\right)$ \\
\hline 2 & Cachoeira Pauli CACB (1) + Rio Grande RIQA (2) & $7.24 \pm 3.28$ & $218.46 \pm 2.34$ & $0.117 \pm 0.016$ \\
\hline 3 & $(1)+(2)+$ Kourou KOUR (3) & $-20.30 \pm 2.10$ & $238.65 \pm 1.90$ & $0.133 \pm 0.009$ \\
\hline 4 & $(1)+(2)+(3)+$ Santiago SAOB (4) & $-20.25 \pm 1.74$ & $238.31 \pm 1.57$ & $0.133 \pm 0.007$ \\
\hline
\end{tabular}

Table 8 Comparison of tectonic plate parameters estimated for selected eight plates for SLR and DORIS techniques in ITRF2008 and for APKIM 2005IGN model and (Larson 1997) GPS technique

\begin{tabular}{|c|c|c|c|c|c|}
\hline Number of stations & Plate & Technique & $\Phi\left(^{\circ}\right)$ & $\Lambda\left(^{\circ}\right)$ & $\omega\left({ }^{\circ} / \mathrm{Ma}\right)$ \\
\hline \multirow[t]{4}{*}{11} & \multirow[t]{4}{*}{ Eurasian } & APKIM2005 & $53.4 \pm 0.4$ & $264.3 \pm 0.5$ & $0.259 \pm 0.001$ \\
\hline & & GPS (Larson) & $56.3 \pm 4.0$ & $257.2 \pm 3.0$ & $0.26 \pm 0.02$ \\
\hline & & DORIS & $55.93 \pm 0.50$ & $266.00 \pm 0.53$ & $0.250 \pm 0.004$ \\
\hline & & SLR & $56.20 \pm 0.56$ & $266.50 \pm 1.00$ & $0.267 \pm 0.004$ \\
\hline \multirow[t]{4}{*}{5} & \multirow[t]{4}{*}{ African } & APKIM2005 & $48.1 \pm 0.3$ & $280.7 \pm 0.8$ & $0.279 \pm 0.002$ \\
\hline & & GPS (Larson) & $50.0 \pm 2.8$ & $273.2 \pm 5.3$ & $0.26 \pm 0.01$ \\
\hline & & DORIS & $49.53 \pm 0.12$ & $283.18 \pm 0.59$ & $0.250 \pm 0.001$ \\
\hline & & SLR & $50.78 \pm 0.22$ & $277.48 \pm 0.52$ & $0.283 \pm 0.002$ \\
\hline \multirow[t]{4}{*}{6} & \multirow[t]{4}{*}{ N. American } & APKIM2005 & $-4.3 \pm 0.6$ & $275.8 \pm 0.2$ & $0.194 \pm 0.002$ \\
\hline & & GPS (Larson) & $-0.4 \pm 4.3$ & $275.5 \pm 2.0$ & $0.21 \pm 0.02$ \\
\hline & & DORIS & $0.80 \pm 0.82$ & $279.50 \pm 0.37$ & $0.200 \pm 0.002$ \\
\hline & & SLR & $-4.97 \pm 0.66$ & $272.71 \pm 0.24$ & $0.183 \pm 0.004$ \\
\hline \multirow[t]{4}{*}{5} & \multirow[t]{4}{*}{ Australian } & APKIM2005 & $32.8 \pm 0.1$ & $36.7 \pm 0.3$ & $0.639 \pm 0.002$ \\
\hline & & GPS (Larson) & $31.4 \pm 1.0$ & $40.7 \pm 3.1$ & $0.61 \pm 0.01$ \\
\hline & & DORIS & $32.23 \pm 0.07$ & $38.00 \pm 0.14$ & $0.617 \pm 0.001$ \\
\hline & & SLR & $31.42 \pm 0.13$ & $39.48 \pm 0.25$ & $0.617 \pm 0.002$ \\
\hline \multirow[t]{3}{*}{7} & \multirow[t]{3}{*}{ Pacific } & APKIM2005 & $-63.2 \pm 0.1$ & $110.5 \pm 0.5$ & $0.671 \pm 0.002$ \\
\hline & & GPS (Larson) & $-63.1 \pm 0.9$ & $95.9 \pm 2.3$ & $0.70 \pm 0.01$ \\
\hline & & DORIS & $-62.20 \pm 0.85$ & $113.70 \pm 3.81$ & $0.650 \pm 0.002$ \\
\hline \multirow[t]{3}{*}{6} & \multirow[t]{3}{*}{ Antarctic } & APKIM2005 & $61.1 \pm 0.5$ & $239.5 \pm 0.7$ & $0.243 \pm 0.004$ \\
\hline & & GPS (Larson) & $60.5 \pm 6.6$ & $234.3 \pm 3.6$ & $0.24 \pm 0.03$ \\
\hline & & DORIS & $60.28 \pm 0.23$ & $235.10 \pm 0.61$ & $0.250 \pm 0.006$ \\
\hline \multirow[t]{3}{*}{3} & \multirow[t]{3}{*}{ South American } & APKIM2005 & $-14.6 \pm 0.9$ & $238.0 \pm 1.5$ & $0.123 \pm 0.002$ \\
\hline & & GPS (Larson) & $-21.0 \pm 7.4$ & $176.5 \pm 29.6$ & $0.16 \pm 0.06$ \\
\hline & & DORIS & $-20.30 \pm 2.10$ & $238.65 \pm 1.90$ & $0.133 \pm 0.009$ \\
\hline
\end{tabular}

stations only; Arequipa (ARFB) station is not stable in last years, and the shift of this station does not agree with the plate motion parameters. For this plate, there is a big difference in comparison with Model APKIM 2005 IGN and our solution equal to 6 degrees for parameter $\Phi$ is observed, probably because the number of stations is not sufficient.
- The results may not be representative for the entire interior of the plates, particularly for stations located in the plates' boundaries. Continuous monitoring of station displacement is recommended, particularly for stations located in micro-plates and plates' boundaries. For these stations, velocities should be treated as 
unknown in the solution. An example is the Monument Peak (MONB) station.

Open Access This article is distributed under the terms of the Creative Commons Attribution 4.0 International License (http://creative commons.org/licenses/by/4.0/), which permits unrestricted use, distribution, and reproduction in any medium, provided you give appropriate credit to the original author(s) and the source, provide a link to the Creative Commons license, and indicate if changes were made.

\section{References}

Altamimi Z, Collilieux X, Métivier L (2011) ITRF2008: An improved solution of the international terrestrial reference frame. J Geodesy 85(8):457-473. https://doi.org/10.1007/s00190-011$0444-4$

Altamimi Z, Collilieux X, Métivier L IERS Technical Note 37, https://www.iers.org/IERS/EN/Publications/TechnicalNotes/ tn37.html?nn=94912

Cox A, Hart RB Plate Tectonics: How it works, Wiley, 1986, ISBN: 978-0-865-42313-8

Cretaux J, Soudarin L, Cazenave A, Bouille F (1998) Present-day tectonic plate motions and crustal deformations from the DORIS space system. J Geophys Res 103(B12):30167-30181. https:// doi.org/10.1029/98JB02239

Drewes H (1982) A geodetic approach for the recovery of global kinematic plate parameters. Bull Geod 56:70-79. https://doi.org/ 10.1007/BF02525609

Drewes H (1989) Global plate motion parameters derived from actual geodetic observations. In: International association of geodesy symposia 101, global and regional geodynamics, Edinburgh, Scotland, August 3-5, 1989

Drewes H. (2009), The Actual Plate Kinematic and Crustal Deformation Model APKIM 2005 as Basis a Non-Rotating ITRF, International Association of Geodesy Symposia 134, SpringerVerlag Berlin Heidelberg 2009, DOI 10,1007/978-3-642-003603_15

Heiskanen W, Moritz H (1981) Physical geodesy. Reprint, Institute of Physical Geodesy, Technical University of Graz

Kraszewska K, Jagoda M, Rutkowska M (2016) Tectonic plate parameters estimated in the International Terrestrial Reference Frame ITRF 2008 Based on SLR Stations. Acta Geophys. https:// doi.org/10.1515/acgeo-2016-0072

Larson KM, Freymueller J, Philipson S (1997) Global plate velocities from the Global Positioning System. J Geophys Res 102:9961-9981

Lejba P, Schillak S (2011) Determination of station positions and velocities from laser ranging observations to Ajisai, Starlette and Stella satellites. Adv Space Res 47:4. https://doi.org/10.1016/j. asr.2010.10.013

Rutkowska M, Jagoda M (2010) Estimation of the elastic earth parameters using the SLR LAGEOS 1 and LAGEOS 2 data. Acta Geophys 58(4):705-716. https://doi.org/10.2478/s11600009-0062-1

Sośnica K (2014) LAGEOS sensitivity to ocean tides. Acta Geophys 63(4):1181-1202. https://doi.org/10.1515/acgeo-2015-0032

Soudarin L, Cretaux J (2005) A model of present-day tectonic plate motions from 12 years of DORIS measurements, (2005), IDS Workshop, 13-15 March 2005 Venice, Italy

Van Gelder BHW, Aardoom L (1982) SLR Network Designs in View of Reliable Detection of Plate Kinematics in the East Mediterranean, Reports of the Department of Geodesy, Delft University of Technology, Delft, The Netherlands 